\title{
¿"Deep-Arvor": A New Profiling Float to Extend the Argo Observations Down to 4000-m Depth
}

\author{
Serge Le Reste, Vincent Dutreuil, And XAVIER André \\ Ifremer, Brest, France \\ VIRGINIE THIERRY \\ Laboratoire d'Océanographie Physique et Spatiale, Ifremer, Plouzané, France \\ Corentin Renaut and Pierre-Yves Le Traon \\ Ifremer, Brest, France \\ GUILLAUME MAZE \\ Laboratoire d'Océanographie Physique et Spatiale, Ifremer, Plouzané, France
}

(Manuscript received 12 October 2015, in final form 16 February 2016)

\begin{abstract}
The international Argo program, consisting of a global array of more than 3000 free-drifting profiling floats, has now been monitoring the upper $2000 \mathrm{~m}$ of the ocean for several years. One of its main proposed evolutions is to be able to reach the deeper ocean in order to better observe and understand the key role of the deep ocean in the climate system. For this purpose, Ifremer has designed the new "Deep-Arvor" profiling float: it extends the current operational depth down to $4000 \mathrm{~m}$, and measures temperature and salinity for up to 150 cycles with CTD pumping continuously and 200 cycles in spot sampling mode. High-resolution profiles (up to 2000 points) can be transmitted and data are delivered in near-real time according to Argo requirements. Deep-Arvor can be deployed everywhere at sea without any preballasting operation and its light weight $(\sim 26 \mathrm{~kg})$ makes its launching easy. Its design was done to target a cost-effective solution. Predefined spots have been allocated to add an optional oxygen sensor and a connector for an extra sensor. Extensive laboratory tests were successful. The results of the first at-sea experiments showed that the expected performances of the operational prototypes had been reached (i.e., to perform up to 150 cycles). Meanwhile, the industrialization phase was completed in order to manufacture the Deep-Arvor float for the pilot experiment in 2015. This paper details all the steps of the development work and presents the results from the at-sea experiments.
\end{abstract}

\section{Introduction}

Long-term, global, and high-quality ocean observations are provided by the international Argo program, whose goal is to maintain in operation 3000 operating profiling floats measuring temperature and salinity in the upper

\footnotetext{
¿ Denotes Open Access content.
}

Corresponding author address: Serge Le Reste, Ingénierie et Instrumentation Marine, Recherches et Développements Technologiques, Ifremer, Z.I. de la Pointe du Diable, CS 10070, 29280 Plouzané, France.

E-mail: serge.le.reste@ifremer.fr
$2000 \mathrm{~m}$ of the world's oceans (Roemmich et al. 2009). Argo thus aims at understanding the role of the ocean on the earth's climate, documenting climate-relevant ocean variability on seasonal to multidecadal time scales, providing better-quality observed fields used to initialize coupled ocean-atmosphere climate models, and constraining ocean analysis and forecasting systems (Freeland et al. 2010).

So far, one of Argo's main achievements has been to improve greatly the estimation of the ocean heat content (Gaillard et al. 2016). Yet, if we want to be able to examine long climate-related time scales and to better quantify the global integrated heat and freshwater content variability, then deeper water masses need to be 


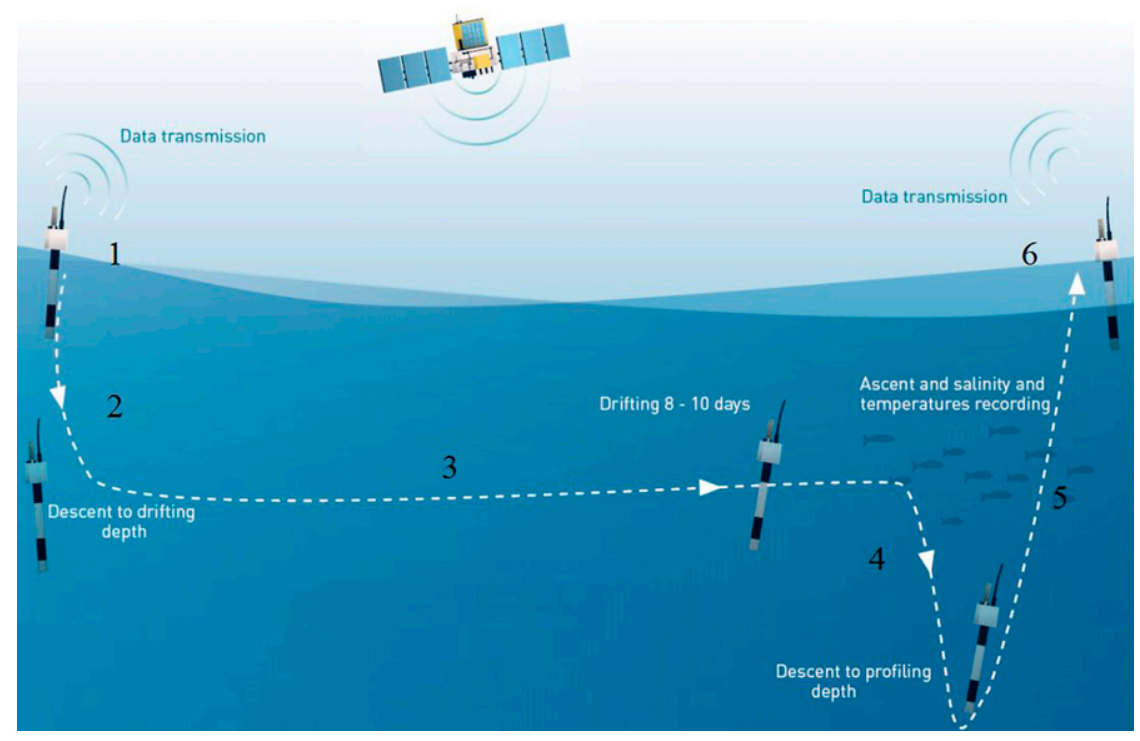

FIG. 1. Typical operational cycle of an Argo profiling float (courtesy of Euro-Argo Research Infrastructure). The float reduces its buoyancy (1), dives (2), and drifts at parking depth (3). Then it travels to the profile depth (4) and makes its measurement during the ascent (5). Transmissions and positioning are done at surface at the end of each cycle (6).

monitored. Recent observation-based studies demonstrated that the warming of the deep ocean below $2000 \mathrm{~m}$ has significantly contributed to the mean sea level rise (Purkey and Johnson. 2010; von Schuckmann et al. 2014). However, these studies were based on deep repeat hydrographic sections that only measure changes in decadal time scales, and better temporal resolutions are needed in the deep ocean to compute regionalized and more precise budgets.

As a result, there is a strong requirement from the ocean and climate research community to expand the Argo coverage into the deep ocean below $2000 \mathrm{~m}$. This was an essential element of the global ocean observing system envisioned by the OceanObs'09 conference (Garzoli et al. 2010; Church et al. 2011).

The profiling float used within the Argo program is an autonomous instrument dedicated to monitor the upper layers of the oceans by measuring pressure, temperature, and salinity during ascending (or descending) profiles between a defined depth (usually $2000 \mathrm{~m}$ ) and the sea surface (Fig. 1). The float vertical displacement is controlled by pressure measurements and is based on its capacity to adjust its density by controlling its own volume without changing its mass. The ascent to the surface lasts a few hours (at a typical speed of about $10 \mathrm{~cm} \mathrm{~s}^{-1}$ ) and occurs typically every 10 days. The gathered data are then transmitted to a data center by satellite telemetry, and the float dives for a new cycle. Between each surfacing, the float behaves as a Lagrangian drifter at its parking depth (usually $1000 \mathrm{~m}$ ). Different types of profiling floats manufactured by different companies have contributed to the Argo program [see Ollitrault and Rannou (2013) for the description of the main models]. Among them, the Arvor float was designed by L'Institut Français de Recherche pour l'Exploitation de la Mer (Ifremer; Loaec et al. 2004; Le Reste and Gould 2011) and manufactured by NKE Instrumentation (Hennebont, France) since 2008.

Recently, Ifremer has designed a deep profiling float able to address the future requirements of Argo. This work was done within the Novel Argo Ocean Observing System (NAOS) project framework that started in 2011 (Le Traon et al. 2012). One of the NAOS purposes is to meet the future scientific challenges set by Argo by proposing innovative technological evolutions. This was a tremendous opportunity to start a "deep" pilot experiment in order to acquire information about the array design and cost feasibility of global deep ocean sampling. In this paper, we describe the development of the Deep-Arvor profiling float, discussing the requirements and describing the results from the first tests at sea. First, we summarize the main choices we made in the design of the instrument and we present key technological developments for the float, and its expected performances, including the energy budget. Second, we present the main validation tests and the results from atsea experiments, which started during summer 2012. To conclude, some improvements are proposed, and the future steps toward a pilot experiment are mentioned. 


\section{Objectives and main choices}

Our motivations for developing a deep float were twofold: to design a new Argo float able to sample the deep ocean in a future Deep Argo component (Zilberman and Maze 2015) and to provide an instrument that could be embedded in the current Argo array, able to replace some of the $0-2000-\mathrm{m}$ floats. The requirements to consider were as follows:

1) The ability to send data in near-real time for operational oceanography, to perform 150 cycles as required within the Argo program, and to perform profiles with higher vertical resolutions than the standard Argo resolution, which is typically $25 \mathrm{dbar}$ at depth.

2) The ease of operability, which based on 15 years of experience within the Argo program, is crucial when testing the instrument before deployment as well as during the maintenance of the Argo array, since many deployments take place using ships of opportunity. Therefore, several aspects had to be considered such as (i) the float dimensions, as the tests were carried out in a hyperbaric pressure tank; (ii) the capability to deploy the float everywhere at sea without any preballasting operation; and (iii) the float weight, in order to facilitate the deployment.

3) The possibility to add sensors for future Argo needs, such as biogeochemical sensors, starting with oxygen sensors used, for instance, to monitor deep convection events (Piron et al. 2016) and water mass pathways, or to estimate long-term oxygen content changes (Gruber et al. 2010; Keeling et al. 2010).

4) An affordable cost, as we planned to commercialize the instrument.

Using ETOPO1 bathymetry (Amante and Eakins 2009), we estimated the volume of the different regions of the global ocean: (i) the coastal area shallower than $2000 \mathrm{~m}$; (ii) the Argo layer, defined as the layer between the surface and $2000 \mathrm{~m}$ excluding the coastal area; (iii) the deep ocean layer, defined as the layers between the 2000- and 4000-m isobaths; and (iv) the abyssal ocean layer for layers deeper than $4000 \mathrm{~m}$. While the coastal area and the abyssal layers represent $2.6 \%$ and $11.7 \%$ of the total ocean volume, respectively, the Argo layer and the deep ocean account for $45.6 \%$ and $39.5 \%$ of the ocean volume, respectively (Fig. 2).

Based on these estimates and on the existing constraints of float design (in particular the cost), it was decided to develop a deep float able to reach $4000 \mathrm{~m}$, which is twice the actual depth of the Argo array. This would help improve significantly estimates of the ocean heat and freshwater content (structure and variability) deeper than

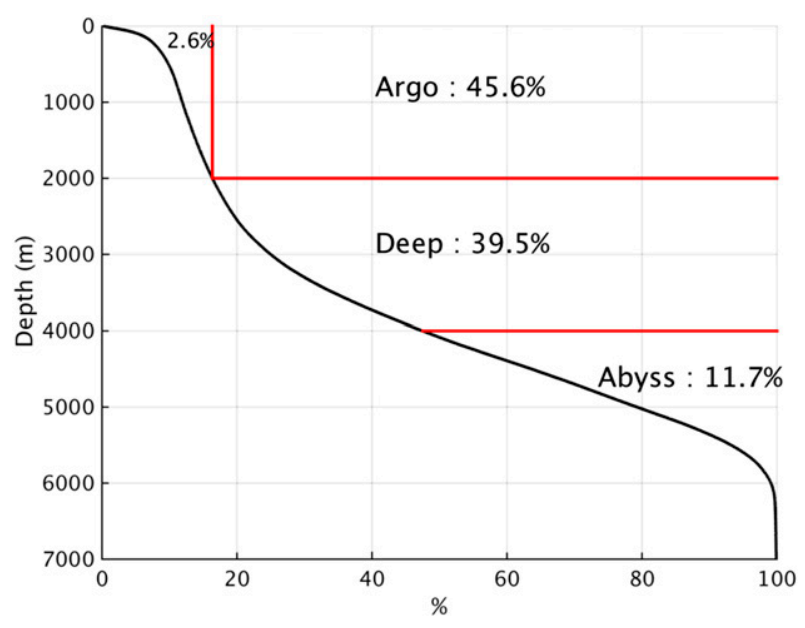

FIG. 2. Ocean surface and volume features. The black curve represents the cumulated surface of the oceans, down from the sea surface to the abyssal, in percentage of the whole surface. The volume of the coastal, Argo, deep, and abyss layers are also indicated. Whereas the depths $>4000 \mathrm{~m}$ cover $50 \%$ of the surface of the oceans, they only represent $11.7 \%$ in volume.

$2000 \mathrm{~m}$ and their contribution to sea level rise in allowing the monitoring of more than $85 \%$ of the total ocean volume and in reducing the large uncertainties in the decadal temperature trend estimated for the 20004000-m layer by Purkey and Johnson (2010) and Kouketsu et al. (2011). Indeed, using ship-based historical measurements, these authors revealed that in the 20004000-m layer the sign and the amplitude of the decadal temperature trend differed in various ocean basins. The sign was not even reliable in many regions of the global ocean [see Fig. 9 in Purkey and Johnson (2010), for instance]. This highlights the need to urgently remove that decadal signal sign uncertainty.

Purkey and Johnson (2010) and Kouketsu et al. (2011) also revealed a significant warming trend below $4000 \mathrm{~m}$, highlighting the climatic role of the abyssal ocean in storing heat over long time scales and advocating the development of full-depth $(0-6000 \mathrm{~m})$ global ocean observations. In this context, it is worth mentioning that ship-based measurements and autonomous platforms with different depth capabilities ( 4000 or $6000 \mathrm{~m}$ ) are not in competition and will complement each other on the path toward the implementation of a deep component in the existing Global Ocean Observing System (GOOS). The design of this deep GOOS component should address heat and salt content issues as well as other objectives, such as the monitoring of deep circulations, for instance (Garzoli et al. 2010), and is still in discussion at the international level (Zilberman and Maze 2015; Johnson et al. 2015; see also the Global Ocean Ship-Based Hydrographic Investigations Program (GO-SHIP)-Argo-International 


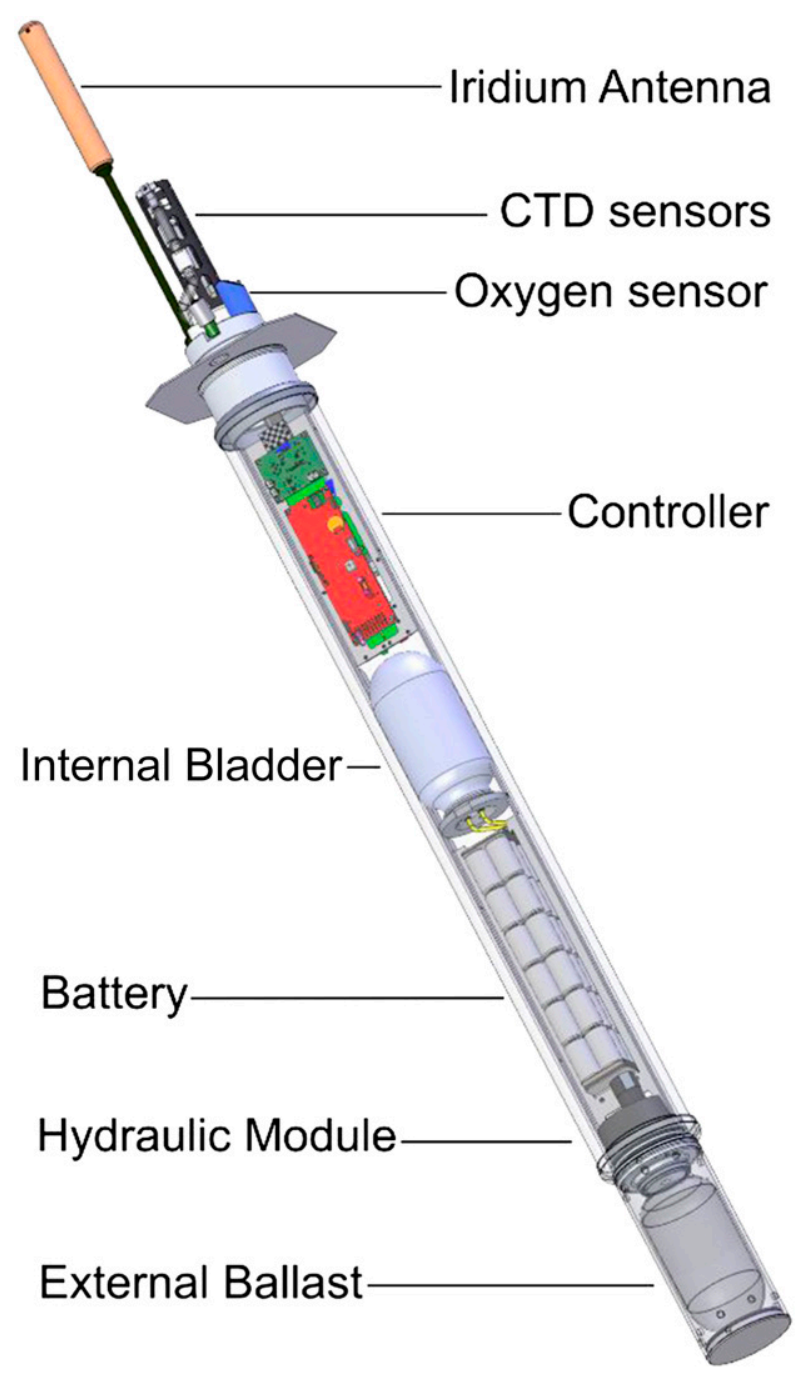

FIG. 3. Deep-Arvor 3D with subsets. This exploded view shows the main subassemblies of the float.

Ocean Carbon Coordination Project (IOCCP) Conference 2015 at http://gaic2015.org/).

\section{Design of the "Deep-Arvor" float}

\section{a. Hardware design}

The design of the float was based on a global approach, as every subassembly of the system is closely linked to the whole system. We also had to manage several nonindependent parameters, including the performance of the engine, the volume of the hull, the embedded mass, the battery, and the amount of data, in order to tackle the different issues discussed in section 2 (Fig. 3).

First, an improved version of the Sea-Bird Electronics (SBE) CTD 41CP was used instead of a more elaborate
TABLE 1. Accuracy and stability of the Deep-Arvor SBE CTD sensor.

\begin{tabular}{lll}
\hline \hline & \multicolumn{1}{c}{ Accuracy } & \multicolumn{1}{c}{ Stability } \\
\hline Conductivity & $0.002\left(\mathrm{~S} \mathrm{~m}^{-1}\right)$ & $0.001\left(\mathrm{~S} \mathrm{~m}^{-1} \mathrm{yr}^{-1}\right)$ \\
Temperature & $0.002\left({ }^{\circ} \mathrm{C}\right)$ & $0.0002\left(\mathrm{C} \mathrm{yr}^{-1}\right)$ \\
Pressure & $7(\mathrm{dbar})$ & $3.5\left(\mathrm{dbar} \mathrm{yr}^{-1}\right)$ \\
\hline
\end{tabular}

and expensive model, following recommendations from the manufacturer Sea-Bird regarding this application, and in particular the required stability up to $4000 \mathrm{~m}$. The titanium sensor base, the conductivity sensor, the temperature sensor, and the pressure sensor (Kistler) are rated to $7000 \mathrm{~m}$. The specifications of the sensors are as follows: temperature accuracy is $0.002^{\circ} \mathrm{C}$ with a stability of $0.0002^{\circ} \mathrm{Cyr}^{-1}$, conductivity accuracy is $0.002 \mathrm{~S} \mathrm{~m}^{-1}$ with a stability of $0.001 \mathrm{~S} \mathrm{~m}^{-1} \mathrm{yr}^{-1}$ (or equivalent salinity), and pressure accuracy is $\pm 0.1 \%$ of full scale range or $7 \mathrm{dbar}$ with a stability of $0.05 \%$ of full scale range or $3.5 \mathrm{dbar} \mathrm{yr}^{-1}$ (Table 1).

During the design of the float, we explored different possible options for the housing. An aluminum alloy cylinder was too heavy and bulky and was not compatible with our pressure test facilities and would have made deployment difficult. First, we tried to use a glass epoxy structure, but the weight saving was still not sufficient. Although the use of a spherical glass hull would have been interesting, we considered that there were risky design aspects, with possible consequences on the hydrodynamic behavior of the float and on the accuracy of the measurements. In fact, it would have been difficult to manage the instrument stability constraint (i.e., the location of its center of gravity) and the requirement to locate the CTD outside the hydrodynamic drag of the float. Eventually, a technology of carbon epoxy filament winding was chosen to make the cylindrical hull, benefiting from its strength and lightness (Trautmann 2013). As a result, the housing was a cylinder of $1200-\mathrm{mm}$ length with a $145-\mathrm{mm}$ external diameter. The interface between the tube and the end caps was ensured by a metal ring stuck at the ends. Electrical insulation between the conductive hull and these metal rings prevented corrosion. This was done by winding a glass fiber layer around the surface of the hull, avoiding a hard coat anodization, which would have been mandatory if some high-strength aluminum alloys, commonly used in oceanographic instrumentation and known for their low corrosion resistance, had been chosen. Furthermore, this lightweight technology meant that the use of an extra flotation foam was not necessary to ensure buoyancy. By means of the finite element method for the design of end caps, we discovered that, using normal aluminum, the stress level was too high; thus, an aluminum alloy of 


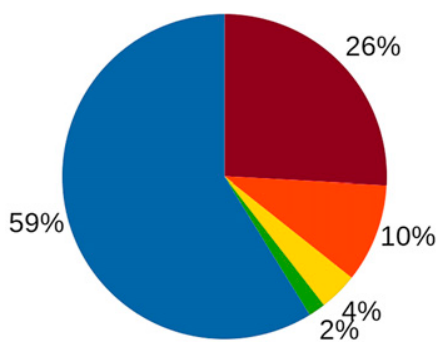

FIG. 4. Energy consumption pattern. The main power is used when the float moves in the water column (blue part). The power consumed when measuring represents a quarter of the total power, which is due to the continuous sampling and pumping of the CTD along the profile.

higher yield strength was chosen. However, this alloy needed a protective sacrificial anode.

One of the main challenges was the design of the hydraulic engine. Regarding the pressure range encountered by the float (which impacts its lifetime), the hydraulic engine had to be as efficient as possible. A good buoyancy capability was also crucial to undertake the various density conditions (density from 1012 to $1035 \mathrm{~kg} \mathrm{~m}^{-3}$ ). A piston-based technology was initially considered, but it did not offer the same performances as a multistroke pump solution. It is worth noting that this technology was also rejected by other float manufacturers in the past. The engine technology of the original Arvor/Provor (Le Reste and Gould 2011) was improved by extending its capacity to higher pressures. As a result, a multistroke pump and a valve were used to transfer oil between an external bladder on the lower end cap and an internal reservoir inside the housing. Its cubic volume had to be decreased when operating at a pressure beyond $4100 \mathrm{dbar}$. A high-efficiency electric motor was chosen to optimize the energy budget: only 4 A were needed to operate the pump at 4100-dbar pressure. The hydraulic circuit was filled with $1.5 \mathrm{~L}$ of oil, in order to meet the needs for buoyancy during surface time for satellite transmission, displacement during the dive, and variability of the manufacturing dimensions of the float, and hence for the range of densities encountered and for avoiding any weighing operation according to the deployment area. During immersion, the hydraulic flow rate of the valve is very pressure dependent (it is expressed as $k \cdot \sqrt{ } P$, with $k$ being a function of the valve geometry); that is why the stroke of the valve was also improved to obtain a higher resolution during immersion motion (better than $\pm 50 \mathrm{~m}$ at $4000 \mathrm{~m}$ ), allowing for an opening time as low as $15 \mathrm{~ms}$.

The upper end cap supports the CTD sensors, the antenna, and a connector (Fig. 3). A hole has been added to place the oxygen sensor (Aanderaa model 4330) when
TABLE 2. Number of profiles that the Deep-Arvor can operate, depending on its configuration: continuous pumping of the CTD or spot sampling, and with or without DO measurements.

\begin{tabular}{llr}
\hline \hline & CTD only & CTD + DO \\
\hline Continuous pumping & 150 cycles & 130 cycles \\
Spot sampling & 200 cycles & 169 cycles \\
\hline
\end{tabular}

needed, and a high pressure connector allows any additional sensor (e.g., biochemical sensors) to be mounted outside the float, for example, along the housing. Data communications are performed thanks to a NAL Research Corporation 9602 Iridium modem working in short-burst data (SBD) mode and connected to an external antenna. This modem also includes a GPS receiver for float localization. The upper part of this antenna is made of a radio frequency-transparent material that receives two sensitive circularly polarized elements: one for the Iridium transmission and the other for the GPS. Finally, a wireless Bluetooth link allows users to program the instrument without any hardware connection.

The controller of the Deep-Arvor is based on an ATmega low-power Atmel microcontroller, supplied by 3.3-V low-drop voltage regulators. These regulators are supplied by a primary voltage of $14 \mathrm{Vdc}$. All the float's functions are set to save energy by using "sleep" modes as often as possible. The peripherals (hydraulics, modem, sensors) are supplied by the primary voltage or a boost elevator and can be switched on and off when requested.

The hull of the float houses the batteries, the oil reservoir, the low-power electronic controller, and the satellite transmitter. The energy budget (Fig. 4) was assessed by performing 150 cycles at $4000-\mathrm{m}$ depth with the continuous pumping mode of the CTD. The use of the "spot sampling" mode (see section $3 \mathrm{~b}$ ) saves up to $30 \%$ of energy, increasing the float's lifetime. The consumption of the optional optode increases the energy budget by $15 \%$ and thus reduces the lifetime of the system (see Table 2). The batteries contain Li-SOCl2 lithium primary cells, offering high current capability, low voltage drop over time, and high capacity versus volume ratio.

The option to perform high-resolution profiles [up to 2000 CTD-plus-oxygen (CTDO) samples] was implemented on the Deep-Arvor. To be able to send more data than with the current Argos-2 System while spending only a few minutes at the sea surface, we chose to use the Iridium satellite communication system.

In some areas, the evolution of the deep water masses is slow and does not require a high sampling period. For this reason, and in order to save energy and hence to increase the lifetime of the float, the ability to perform "alternate" cycles was implemented in the Deep-Arvor. This feature 
allows the user to program the float to start its profile at two different profiling depths, and to perform a deep profile only every $N$ cycle. For example, the float can dive to $4000 \mathrm{~m}$ every five cycles, the four other cycles are performed at a standard 2000-m depth.

\section{b. Functional features}

The algorithm driving the Deep-Arvor has a sequential mode to ensure a robust behavior (see Fig. 1). After a period when good buoyancy is required for satellite transmissions, buoyancy reduction occurs. It is optimized to be as fast as possible (about $20 \mathrm{~min}$ ), thanks to a self-adaptive algorithm. Then, the descent to the parking depth is controlled by successive valve actions, based on the nonevolution of the pressure coupled with the computation of the float weight increase. During the drift, pressure of the float is regularly (i.e., every $10 \mathrm{~min}$ ) measured in order to compare its position to the user's setup. If a difference occurs at two consecutive samples, then the float is repositioned. After the drift, the float dives to reach its programmed profile depth, that is, up to $4100 \mathrm{dbar}$. If the pressure exceeds an emergency level (typically the maximum profile pressure +100 dbar, i.e., $4200 \mathrm{dbar}$ ), then an ascent algorithm repositions the float at its operating pressure. Then the profile starts, controlling the ascent speed in order to maintain it at a value close to $9 \mathrm{~cm} \mathrm{~s}^{-1}$. If the float reaches the seabed during its descent to the parking or profile depths, then two different programmable behaviors occur: either the float can stay on the seabed, until the time of the next ascent profile (option 1), or it can reach a lower parking depth and then drift at this immersion (option 2). It is worth noting that the grounding is not expected to be problematic regarding the quality of the measurements and the lifetime of the Deep-Arvor. As the sensors are positioned on the top of the float, they will not be damaged during grounding. Furthermore, the descent speed is a few centimeters per second. When the float hits the bottom, its weight is very low (a few tens of grams) and it takes off rapidly after grounding (in less than $10 \mathrm{~min}$ ) to reach a lower parking depth. The probability of grounding increases with depth, and the second option is the best way to stay the shortest time on the seafloor before taking off. The success of this grounding management has already been demonstrated in the 0-2000-m Arvor float.

The CTD data (and oxygen, if present) are sampled along the profile according to the following method. The CTD returns a sample every $2 \mathrm{~s}$. The float controller picks up one sample every $10 \mathrm{~s}$ (default value; i.e., approximately every meter) and then returns to the sleep mode to save energy. The water column is divided into three layers (deep, intermediate, and near-surface area) whose limits are programmable. In each layer, the samples are averaged into slices whose thicknesses are programmable with 1-dbar resolution. In the deep layer, the data are generally averaged, whereas in the nearsurface area, the data are kept in raw conditions. As a maximum of 2000 CTDO levels can be gathered into SBD messages to be transmitted, the data are usually averaged into slices of a few decibars (e.g., every 20 or $10 \mathrm{dbar}$ ) in the deep and intermediate layers, whereas 1-dbar data points are kept at the near-surface area. This working mode starts from the depth and finishes at the surface, with the CTD pumping continuously. The CTD stops its pumping when the programmable cutoff pressure is reached (typically $5 \mathrm{dbar}$ ), so as to prevent dirt from depositing on the sensors. An alternative to the continuous sampling mode is the "spot" sampling mode. This method consists of activating the CTD pump only when the float reaches each level of target pressure (the middle of every slice). When using this mode, the pump is activated a few seconds before sampling in order to flush the measurement cell. However, this method provides only discrete measurements, while the continuous mode integrates the entire water column, which is more appropriate for heat content monitoring. Finally, when the float is fitted with an oxygen sensor, and oxygen acquisition is set up, the controller picks up the data coming from the optode at the same rate as the CTD (i.e., every $10 \mathrm{~s}$ ). To save energy, the optode is powered off after delivering each sample.

After reaching the surface, the float inflates its ballast in order to obtain enough buoyancy for the antenna to transmit the data through the Iridium satellite communication system. At every surfacing, all the parameters can be remotely controlled through the Iridium downlink: depths, period of cycling, data slice characteristics, optode acquisition or not, alternate mode (e.g., 1 cycle at 4100 dbar every $N$ cycle at 2000 dbar), etc.

To improve the performance of the float, it is crucial to understand the behavior of the Deep-Arvor during tests in real conditions at sea. A total of 91 parameters for technical information (Fig. 5) have been added to the data, including all the significant moments when the sequential phases change (transmission, start of descent, start of ascent, grounding, etc.) and when the hydraulic system is activated. They also include the status of the sensors and the transmission system. Thanks to this information, the total cycle can be monitored and the data can be used to examine, for instance, the trajectory of the float (Ollitrault and Rannou 2013). The user can program the pressure when the CTD pump stops running ( 5 dbar typically) and the last pumped raw data (CTDO) are transmitted to complete the end of the profile to obtain "near surface" data. The main parameters we have discussed 


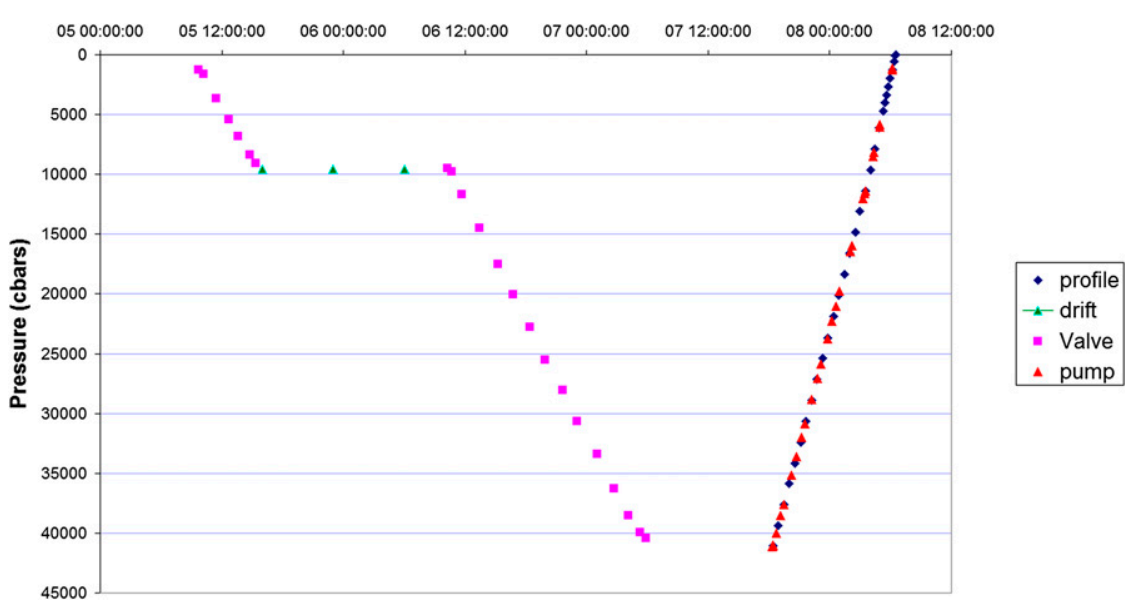

FIG. 5. Technical data sent by the float. Actions carried out by the engine are mentioned with the pink square and red triangle signs. The green triangle represents the measurements done during drift at parking depth. The blue lozenge sign represents measurements that are dated during profile.

above are illustrated in Table 3; they offer a great amount of flexibility to Deep-Arvor users.

\section{Laboratory tests}

The subassemblies underwent functional and environmental tests with special attention given to the new hydraulic engine and the cylindrical hull. The CTD sensor was checked in a calibration laboratory. A dedicated test bench was developed to validate the embedded software. Finally, global and functional environmental tests were conducted.

\section{a. Sensor evaluation}

The SBE 41CP sensor (serial number 2820) placed on the first Deep-Arvor prototype (float WMO 6901468) was calibrated by the Ifremer calibration laboratory at $3.3^{\circ}$ and $15.3^{\circ} \mathrm{C}$, at a salinity of 37.85 and at atmospheric pressure (Salvetat 2011). The difference between the reference temperature provided by a periodically calibrated Rosemount platinum thermometer and the SBE $41 \mathrm{CP}$ temperature sensor was less than $0.001^{\circ} \mathrm{C}$. The difference between the SBE $41 \mathrm{CP}$ conductivity sensor and the reference salinity estimated with a calibrated Guildline Instruments salinometer was -0.007 , which is

TABLE 3. Table of the main programmable parameters for the Deep-Arvor.

\begin{tabular}{|c|c|c|c|}
\hline Parameter & Default & Min & Max \\
\hline Number of cycles & 500 & 0 & 500 \\
\hline Period of cycle (day) & 10 & 1 & 20 \\
\hline Sensors sampling period at descent $(\mathrm{s}),(0$ : no measurement $)$ & 10 & 0 & 600 \\
\hline Sensors sampling period at parking $(\mathrm{h}),(0$ : no measurement $)$ & 12 & 0 & 48 \\
\hline Sensors sampling period at ascent (s), (0: no measurement) & 10 & 0 & 600 \\
\hline Parking pressure (dbar) & 1000 & 10 & 4100 \\
\hline Profile start pressure (dbar) & 4100 & 10 & 4100 \\
\hline Threshold pressure between surface and intermediate area (dbar) & 10 & 10 & - \\
\hline Threshold pressure between bottom and intermediate area (dbar) & 200 & 10 & - \\
\hline Interval for data bin averaging within surface area (dbar) & 1 & 1 & - \\
\hline Interval for data bin averaging within intermediate area (dbar) & 10 & 1 & - \\
\hline Interval for data bin averaging within bottom area (dbar) & 25 & 1 & - \\
\hline End of mission transmission period $(\mathrm{mn})$ & 60 & 5 & 2880 \\
\hline Alternate cycle period (number of cycles), (1: only one profile period) & 1 & 5 & 20 \\
\hline Profile start pressure of the alternate cycle (dbar) & 4100 & 10 & 4100 \\
\hline Sensors' acquisition mode (1: continuous mode; 2 : spot sampling mode) & 1 & 1 & 2 \\
\hline Oxygen measurement option ( $0:$ no; 1 : yes) & 0 & 0 & 1 \\
\hline $\begin{array}{l}\text { Grounding behavior option ( } 0 \text { : the pressure set point is decreased } \\
\text { automatically; } 1 \text { : the float is grounded until the time of ascent) }\end{array}$ & 0 & 0 & 1 \\
\hline
\end{tabular}



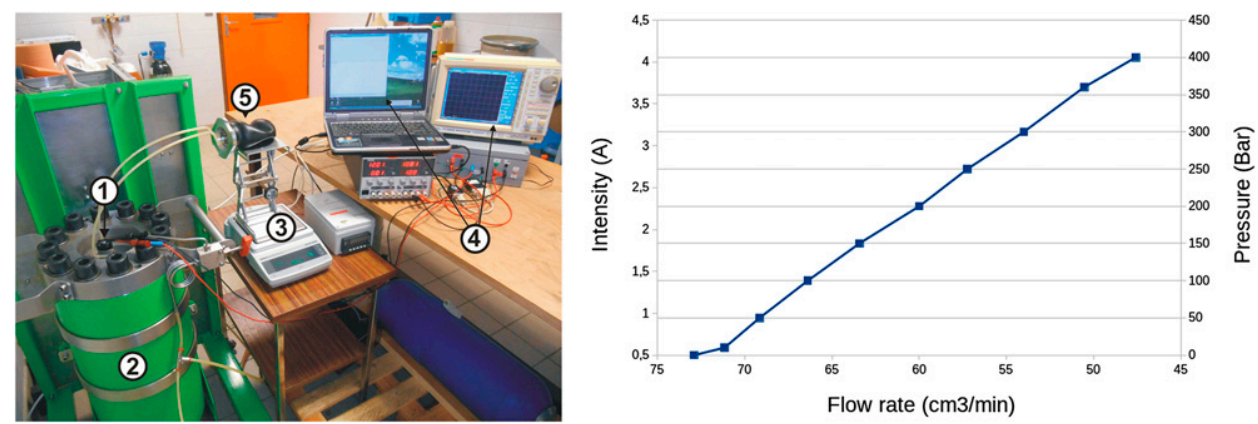

FIG. 6. (left) Hydraulic test bench used for the assessment of the pump efficiency. Hydraulic end cap under test (1). Hyperbaric test tank (2). Scales to weigh the oil transfers during pump or valve activations (3). Computers and oscilloscope for monitoring and control (4). Oil reservoir (5). (right) Current absorbed by the pump during oil transfers.

above the manufacturer's specifications (see section 3a) but lower than the Argo requirements, which expect uncorrected salinities to be as accurate as \pm 0.01 psu.

\section{b. Engine characterization}

Motorization performances (i.e., flow rate and supply current) were assessed by endurance tests. The hydraulic end cap was installed on a pressure tank generating hydrostatic pressure (Fig. 6). This tank was specially designed to maintain its internal pressure stable when the ballast volume varied. When opening the valve or activating the pump, the volume of oil transfers was measured by weighing the reservoir and covering the whole operating pressure range. This useful tool helped us look for the best way to operate the hydraulic engine, and we were able to find out adjustments of supply voltages, pump timings, and valve commands, as well as assess flow rates and currents, and calculate the energy budgets versus the operating pressures.

\section{c. Tests of the housing}

The composite material of the housing was checked by tests in a pressure tank. First, its ability to withstand pressure was tested, by sticking gauges all around (Fig. 7) to monitor the deformations until implosion (above 700 bar). Variation in the hull's volume versus pressure was assessed, using the following method. Before its immersion in the hyperbaric tank, the hull was filled with water. Then, the water was pushed due to the rise in pressure through a capillary tube into the open air, and the volume expelled could be measured in a test tube. Finally, the capacity of the hull to do cycles was tested by performing more than 150 cycles in the hyperbaric tank.

\section{d. Validation of embedded software}

A dedicated laboratory test bench (Fig. 8) was developed in order to qualify the embedded software of profiling floats such as the Deep-Arvor, by stimulation of the float controller (electronic board and software) in near-real conditions. The hydraulic commands of the float were monitored by a man machine interface on a computer that simulated in real time the marine environment of the float and computed its displacements every second. When a hydraulic action occurred, the simulator measured its duration, took the laws of flow
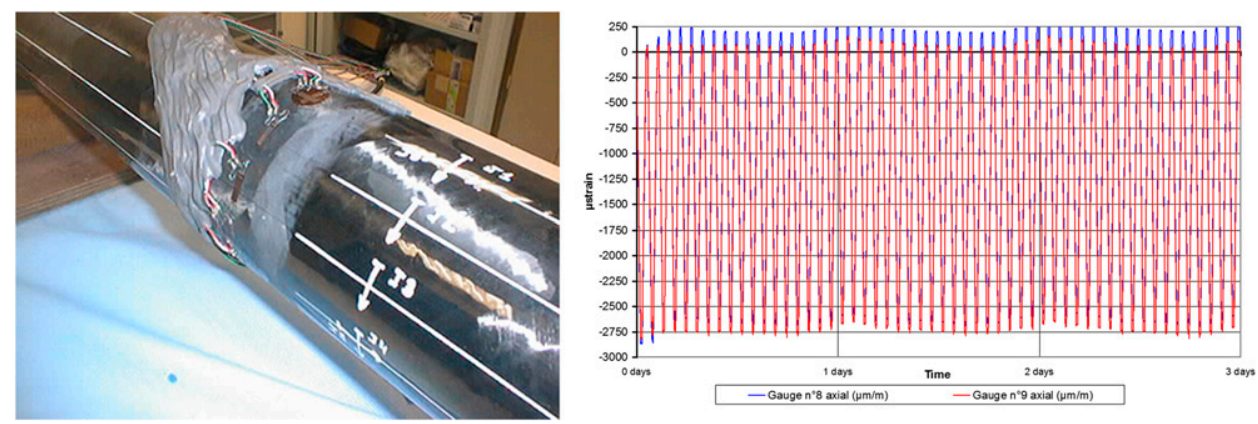

FIG. 7. Testing the tube in the pressure tank. (left) Before the test the tube is fitted with strain gauges stuck around the hull. (right) During the test deformations of the gauges are measured ( $\mu$ strain) while pressure cycles are applied by the pressure tank for 3 days. 


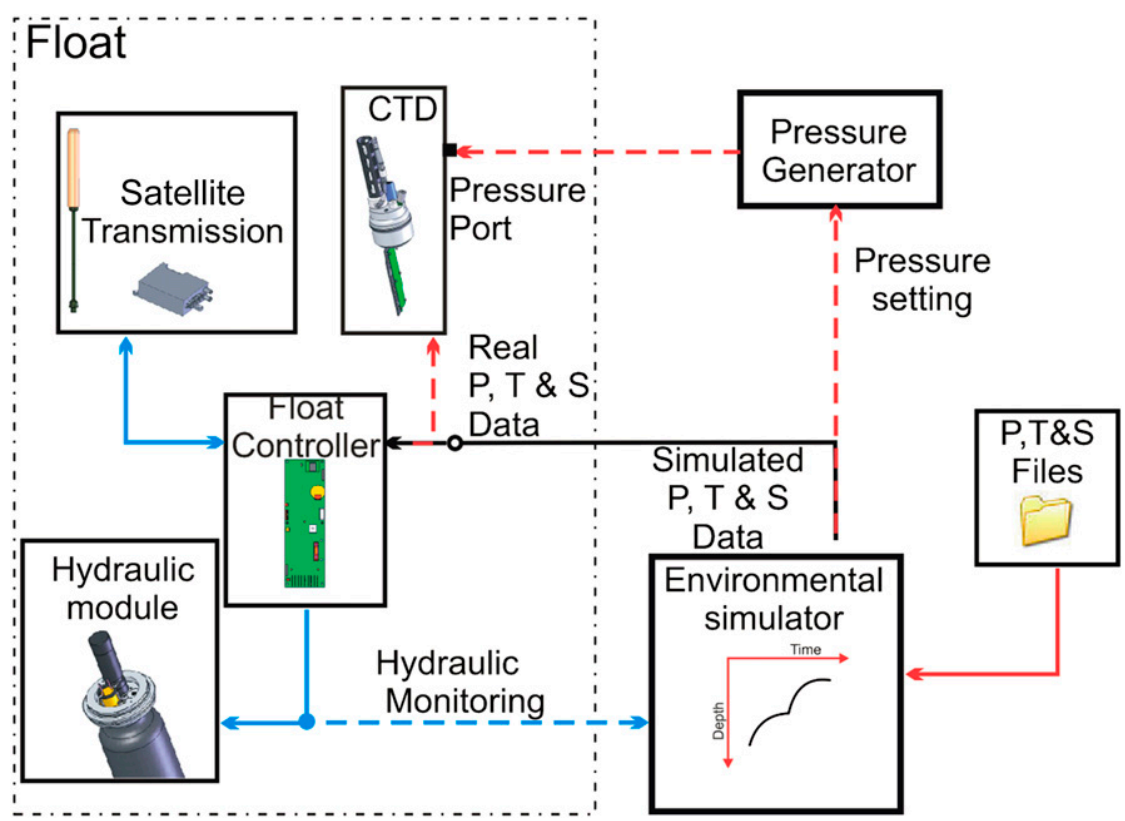

FIG. 8. Environmental test bench for the embedded software. The float part (surrounded by a dashed black line) is in operational mode. The environmental simulator continuously monitors the activations of the float engine, and hence computes the pressure to be applied to it according to the laws of motion of the float. Thus, a whole mission can be performed in a simulated environmental situation.

versus pressure into account, and then calculated the new pressure the float was supposed to reach. Thus, every time the float controller tried to obtain the current pressure (which is delivered by the pressure sensor in normal conditions), the simulator returned an updated pressure computed by the hydrodynamic model of the float displacement in the water. This "environmental" simulator was also used to control a pressure generator, which was plugged into the pressure port of the real CTD sensor, thus taking into account the acquisition electronics of the sensor. The software of the float was subjected to various scenarios, over a long period of time, with real-time or accelerated cycles. After each cycle, the data were transmitted via satellite in order to test the whole system.

\section{e. Tests of the full Deep-Arvor prototypes}

Three different tests were done in our pressure tank. The first one aimed at checking the Deep-Arvor ability to withstand maximal operating pressure, to which a safety margin was added (i.e., 417 bar). The purpose of the second test was to qualify the hydraulic flow (Fig. 9): the float was suspended from a high pressure precision balance ( $5 \mathrm{~N}$ range) and was specifically programmed to activate its pump and valve at some given pressures, causing a variation in float weight measured by the balance. By comparing the weight and the actions, it was possible to validate the commands and characteristics of the hydraulic circuitry. The third test was a fully operational test in the pressure tank: the operator monitored the changes in the float's weight during the experiment (still measured via the balance), and subsequently modified the pressure in the tank. The Deep-Arvor made a real-time or accelerated cycle under pressure, like at sea. This completed the final qualification of the hydraulic behavior of the float, as well as the embedded software (emergency ascent, overshoot control, etc.), although the qualification of the software had already been done on the test bench (section 4d).

\section{Results of the at-sea experiments}

Four Deep-Arvor floats were deployed in the northeastern Atlantic Ocean (see Table 4; Fig. 10). In this region, the deep water masses are stable, thus allowing the quality and behavior of the CTD and oxygen sensors in the deep layer to be assessed. The first two floats were restricted to operate at $3600 \mathrm{dbar}$, as they were the first step in our technological development, while the other two were fully operational at $4100 \mathrm{dbar}$.

The first one (float WMO 6901468) was deployed on 23 August 2012 in the middle of the Atlantic Ocean from the R/V Thalassa during the Strasse cruise. During the first weeks of its mission, the float was remotely controlled 

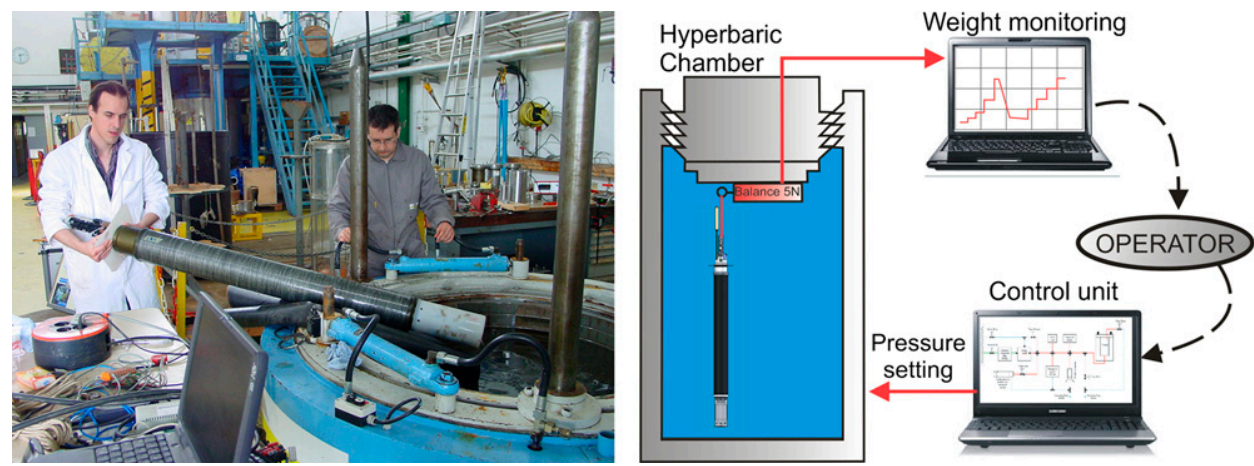

FIG. 9. Operational mission in pressure tank. The float is suspended in a hyperbaric tank and its weight is measured by a balance. The operator takes this weight into account and controls the pressure set point of the tank. Thus, a whole mission can be performed in realistic conditions.

and programmed cycle after cycle to incrementally increase its depth, in order to check the data before the beginning of a new cycle. This first prototype has cycled every 2 days most of the time and completed 60 cycles to 3500 dbar.

A second prototype (float WMO 6901597) was deployed in the Bay of Biscay in October 2012. A decrease in the telemetry performance led us to retrieve it after 4 months of drifting. This allowed us to fix an intermittent failure of the antenna and to correct the process in view of future manufacturing. We also took advantage of this retrieval to examine the overall condition of the float. Despite the presence of fouling caused by its long stay at the surface, it looked in good condition with no abnormal corrosion. This float was deployed again in the Bay of Biscay in November 2013. After almost 80 cycles at $3500 \mathrm{dbar}$, the float drifted toward the continental slope. According to the technical data, it was sometimes dragged along the steep slope by the current.

The third prototype (float WMO 6901631) was deployed on 23 May 2014 in the Iberian basin. In July 2014, the cycle period was set at 10 days to monitor the stability of immersion and the behavior of the temperature $T$ and salinity $S$ measurements at parking depth. The fourth prototype (float WMO 6901632), identical to the third one, was deployed on 31 May 2014 (Fig. 11) in the western European basin. It was set to cycle with a short period (every 2 days) in order to obtain a rapid feedback on the energy balance of the float. In March 2015, after 142 cycles, the batteries were almost flat; thus, a remote command was sent to ensure it stays at the surface for possible future recovery.

\section{a. Float behavior}

Float behavior showed good reproducibility. The regularity of the temporal cycles, the stability of the floats at parking depth, and the quality of data transmission were very satisfying (Fig. 12). The parking depth and the starting profile depth were reached with very few overshoots $(<10 \%$ of the descent phases), indicating good control of the descent phase. The drift at the parking depth interval $( \pm 50 \mathrm{~m})$ was particularly stable: only six corrections were made to maintain the float within the defined interval during the 300 days of drifting (float WMO 6901631).

The ascending profile was done at a speed of $9 \mathrm{~cm} \mathrm{~s}^{-1}$ with a standard deviation of $0.5 \mathrm{~cm} \mathrm{~s}^{-1}$. On average, about 30 pump actions were needed between $4000 \mathrm{~m}$ and the surface.

The analysis of the satellite communications showed that the system spent less than $5 \mathrm{~min}$ to transmit a low-resolution profile ( $\sim 200$ CTDO samples $=\sim 1600$ bytes $)$ and $15 \mathrm{~min}$ to transmit a high-resolution profile $(\sim 1000$ CTDO

TABLE 4. Experiments of the first four prototypes at sea. The first two were operational at 3500-m depth and the last two were operational at 4000-m depth. WMO 6901632 made 142 cycles, including 63 cycles with DO measurements, showing the capability of the Deep-Arvor to meet the specification of 150 cycles at 4000-m depth with CTD measurements.

\begin{tabular}{lcccr}
\hline \hline WMO No. & Deployment date & Operating depth $(\mathrm{m})$ & Period of cycles (days) & No. of cycles done \\
\hline 6901468 & 23 Aug 2012 & 3500 & 2 & 60 \\
6901597 & 17 Nov 2013 & 3500 & 2 & 80 \\
6901631 & 23 May 2014 & 4000 & 10 & 32 \\
6901632 & 31 May 2014 & 4000 & 2 & 142 \\
\hline
\end{tabular}




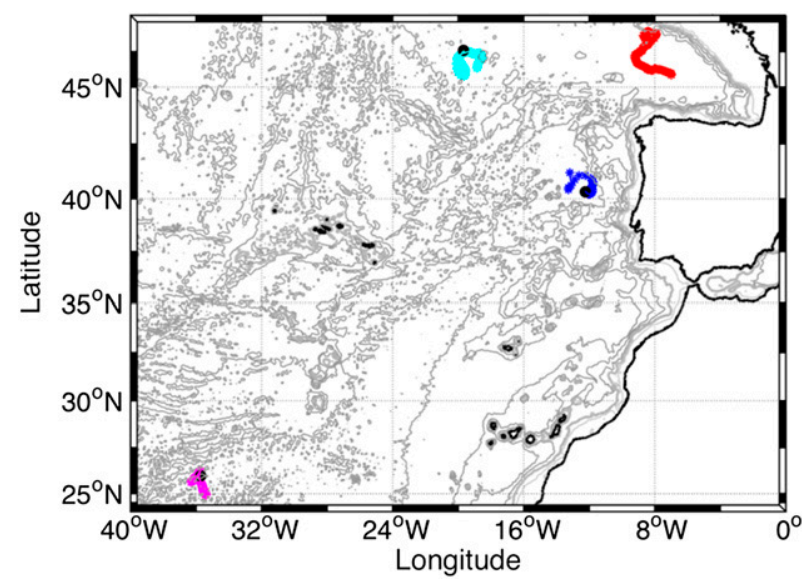

FIG. 10. Position of the four Deep-Arvor floats deployed in the northeast Atlantic Ocean since 2012: WMO 6901468 (magenta), 6901597 (red), 6901631 (blue), and 6901632 (cyan). Black dots near each float represent the position of the reference profiles collected at float deployment (when available).

samples $=\sim 8$ kbytes). The time spent by the GPS receiver to obtain the position from a cold restart was $70 \mathrm{~s}$ on average. The total time spent at the surface, including buoyancy management, was approximately $35 \mathrm{~min}$ for a low-resolution profile.

\section{b. Temperature, salinity, and dissolved oxygen data analysis}

Temperature, salinity, and oxygen profiles collected by the four floats (displayed in Figs. 13 and 14) show the overall good quality of the transmitted data.

Based on pressure measurements performed during the surfacing period, the pressure values are corrected on board by the float itself. The transmitted surface pressure value corresponds to the absolute pressure sensor bias, as the pressure sensor is not reset at each cycle and is used to check the evolution of the pressure sensor. These surface values do not exceed 2 dbar between each cycle on each float, showing no anomalies in sensor behavior.

Except for float WMO 6901597, a reference CTDdissolved oxygen (DO) cast performed simultaneously to the float deployment when possible or later on during the cruise, in order to estimate the sensor biases (Fig. 15). As the CTD cast was done a few days after deployment (float WMO 6901468) or as the float dived progressively down to $4000 \mathrm{~m}$, the time lag between the reference profile and the nearest float profile, with depth equaling 3500 or 4000 dbar (depending on float capability), varied between 7 days (float WMO 6901631) and 5 months (float WMO 6910468). In all cases, the distance between the reference profile and a float profile was less than $20 \mathrm{~km}$.

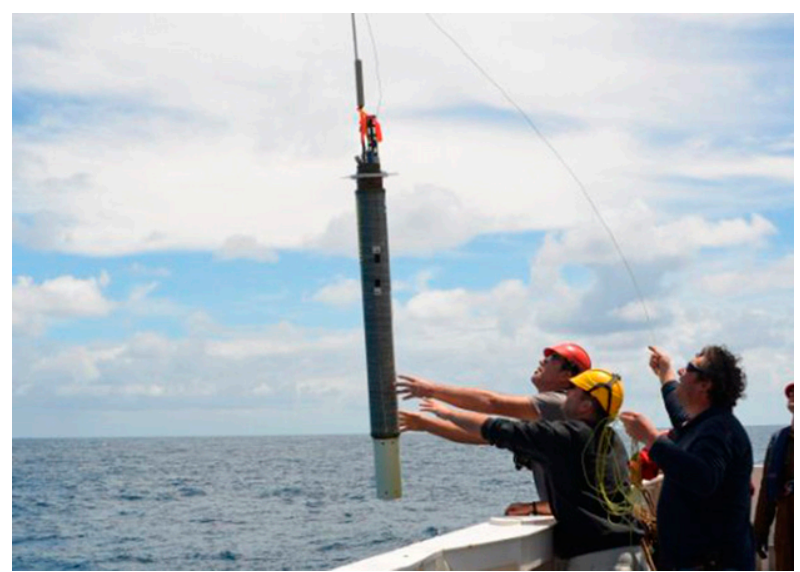

FIG. 11. Deep-Arvor deployment during Geovide cruise, May 2014. The float is suspended by its damping collar with a handling rope and then launched at the sea surface by means of a trigger snap shackle.

As for regular profiling floats (performing profiles down to 2000 dbar), the Aanderaa optode reported dissolved oxygen data biased toward lower values (Takeshita et al. 2013), despite multipoint calibrations performed on the oxygen sensors of floats 6901631 and 6901632. More accurate measurements (including at atmospheric pressure) are required to evaluate the behavior of the oxygen sensor at pressure greater than 2000 dbar. Thus, in-air measurements will be implemented in the future version of the Deep-Arvor in order to recalibrate the sensor when the float surfaces (Bittig and Körtzinger 2015). As a consequence, oxygen data are not discussed further in the remaining part of the paper.

The comparison of the float profiles with the reference profile in a $\theta / S$ diagram (Fig. 15) suggests a bias in the float salinity data in the range of 0.01 or more for the four floats. This bias is equal or larger than the expected sensor accuracy (see section 3a). Considering the amplitude of the bias, we hypothesized that the bias amplitude is not due to a pressure effect but to a bias of the conductivity sensor itself. The conductivity sensor bias (and its potential drift) is estimated following the Owens and Wong (2009, hereafter OW) method, developed for the delayed mode quality control of Argo floats. A modified version of the OW method is used here for the North Atlantic Ocean, following the recent implementation of Cabanes et al. (2016, manuscript submitted to Deep-Sea Res.), which allows for a better error estimate. For all floats, the conductivity sensor bias is first estimated by considering levels below 3000 dbar. According to the OW method, the four floats are biased toward fresher values. The bias varies between $0.009 \pm 0.002$ and $0.020 \pm 0.002$ (Table 5), 


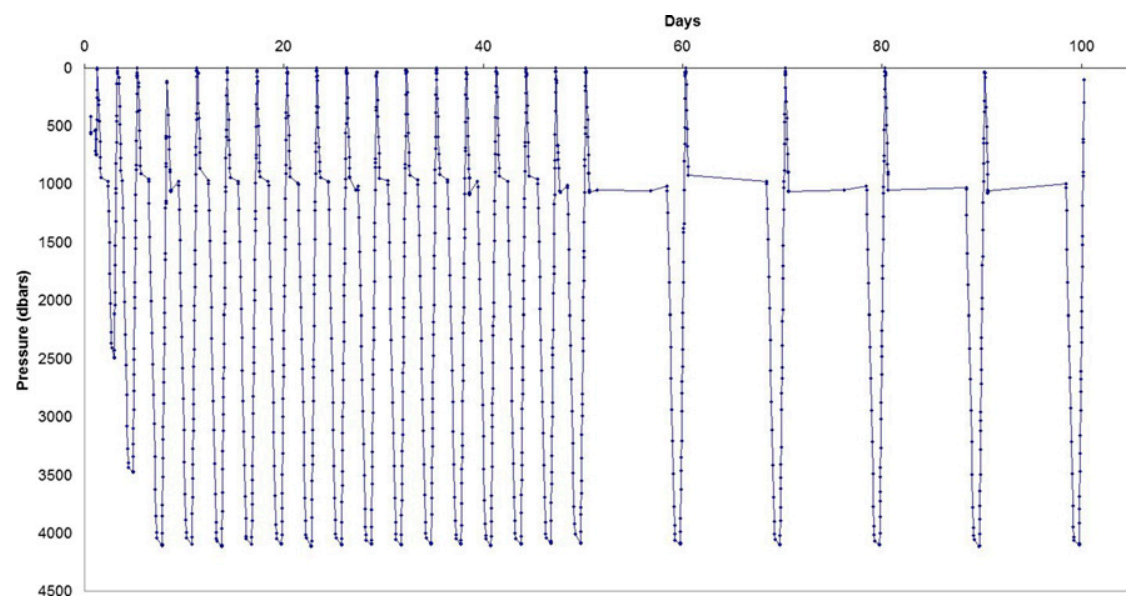

FIG. 12. Vertical behavior of the float. This partial figure illustrates the behavior of the float for the first 3 months and the effect of remote commands that are sent in order to modify its mission scheme.

and it is consistent with the estimation made when comparing the reference profile with the nearest float profile at pressure greater than $3000 \mathrm{dbar}$ (Table 5). The OW method is then applied by considering levels shallower than 2000 dbar (Table 5) as for a regular Argo float. The two estimates are consistent within error bars, which are quite large because of the Mediterranean water signature when considering the 0-2000-m layer and because the floats remained in the same area, thus reducing the number of degrees of freedom used to estimate the amplitude of the error bars (Cabanes et al. 2016, manuscript submitted to Deep-Sea Res.).

The correction proposed by the OW method is further confirmed by the good match of the $\theta / S$ diagram of the reference profile with the nearest float profile after
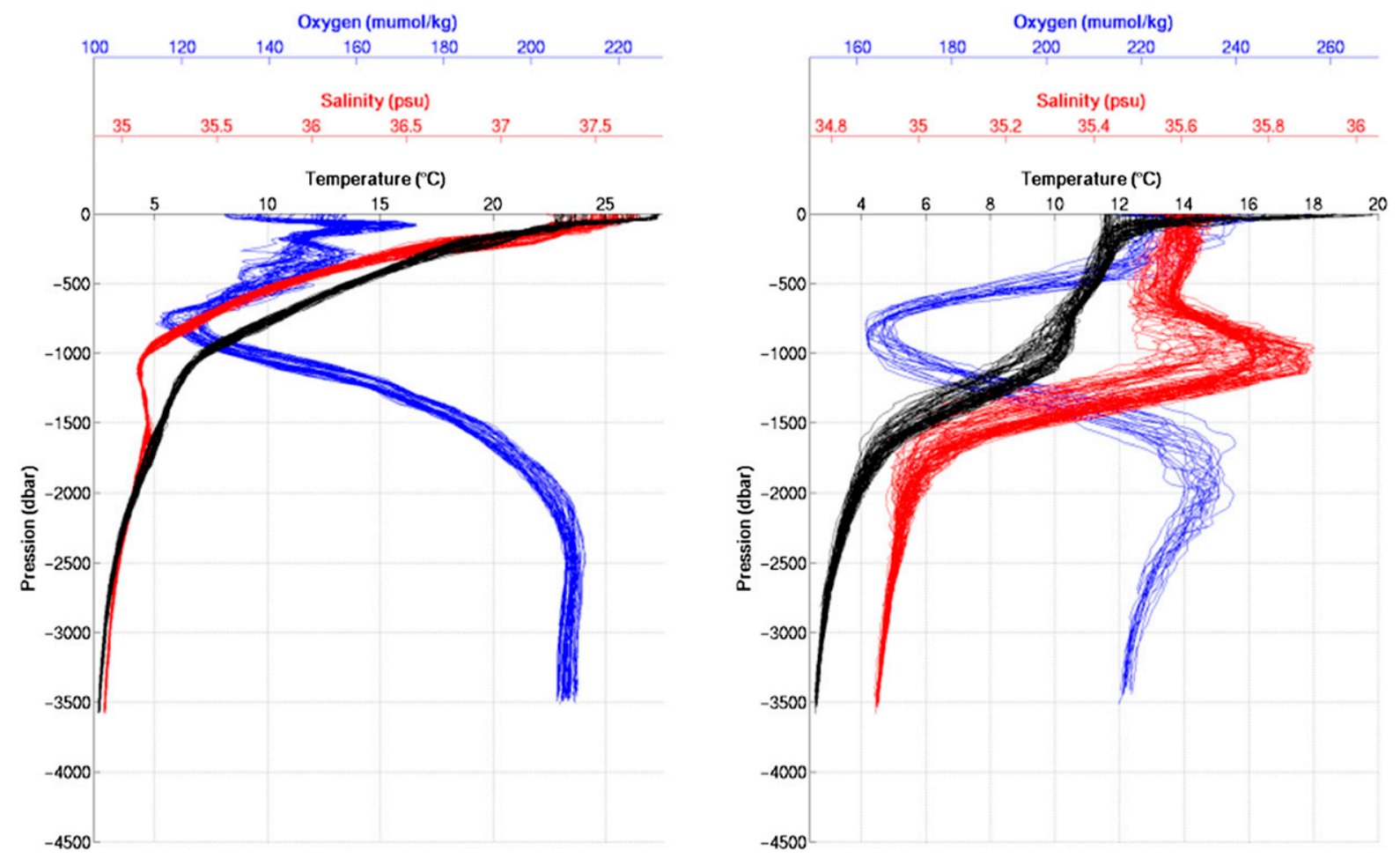

FIG. 13. Potential temperature $\left({ }^{\circ} \mathrm{C}\right)$, salinity, and DO concentration $\left(\mu \mathrm{mol} \mathrm{kg}{ }^{-1}\right)$ vs depth $(\mathrm{m})$ for the first two Deep-Arvor floats: (left) WMO 6901468 and (right) WMO 6901597. 

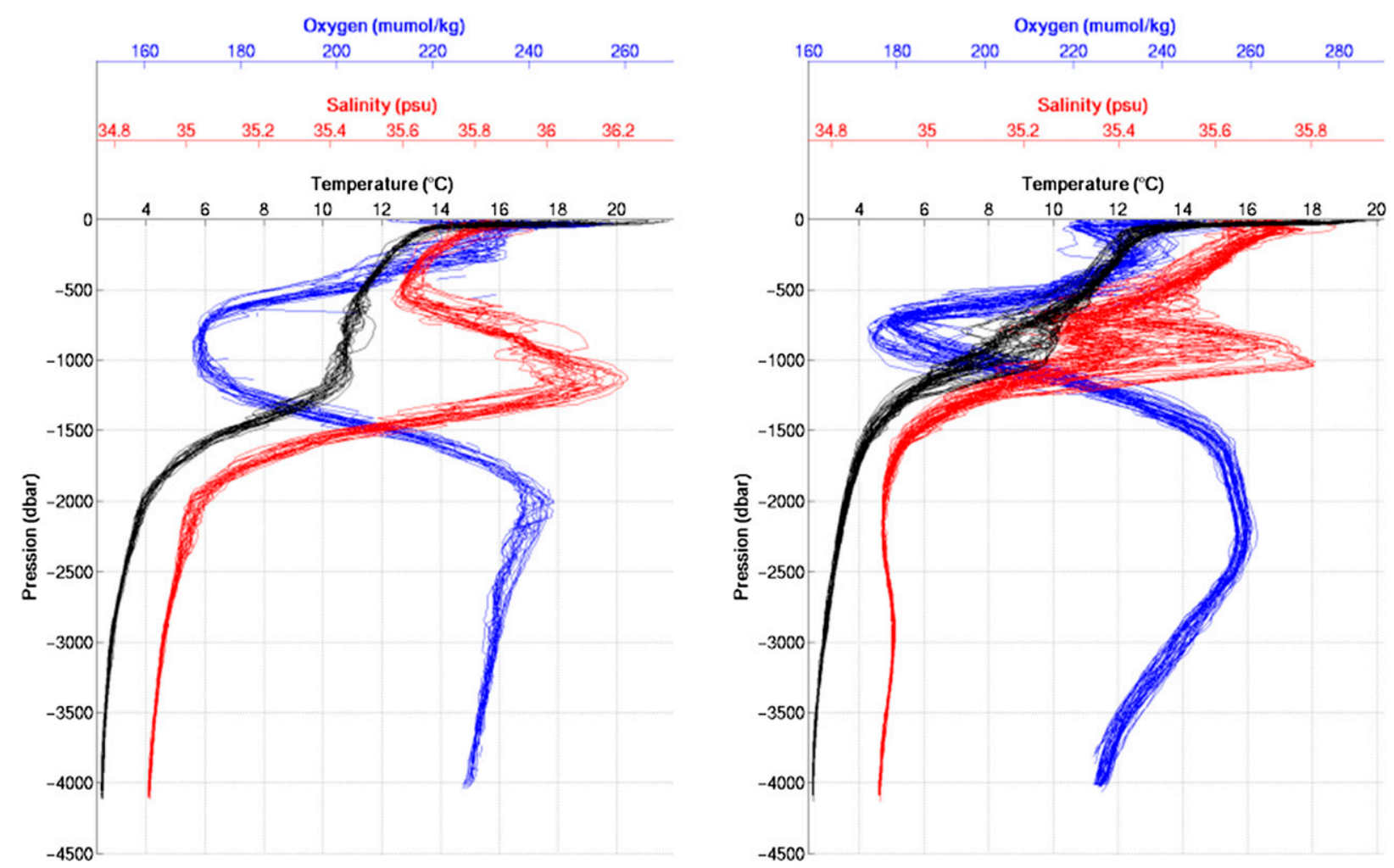

FIG. 14. As in Fig. 13, but for (left) WMO 6901631 and (right) WMO 6901632.

correction (see, e.g., Fig. 15, lower right). In addition, when considering float 6901468 , the fresh bias of $0.009 \pm$ 0.002 is consistent with the estimation from the calibration test at atmospheric pressure in the laboratory (see section 4a).

If we consider that the saline bias is not related to the deep profiling float but to the sensor itself, then these results show that the $0.01-0.02$ fresh bias would not have been detected with a $0-2000-\mathrm{m}$ float in three (out of four) floats. They also reveal that deep profiling capability will be helpful in improving salinity data in the Argo dataset in detecting conductivity sensor bias of small amplitude.

\section{Discussion}

The choice of the 4000-m-depth target was a compromise between the increased performance (more than $85 \%$ of the ocean volume could be monitored) and the evolution of the technology, the ease of operability, and the costs.

The Deep-Arvor profiling float is able to measure salinity, temperature, and oxygen down to 4000-m depth ( $\sim 4100$ dbar) and to perform high-resolution profiles (up to 2000 points) when required. The main measurements are made during the ascent profile and are thus transmitted to shore in near-real time (a few minutes after arrival at the surface) according to the Argo program recommendations, but they can also be made during the descent and the stay at the parking depth. The handling of the float is easy due to its light weight $(26 \mathrm{~kg})$. Extra sensors can be externally added. Many parameters are programmable, like profile and parking depths, cycle period, vertical sampling frequency during profiling and drifting phases, and grounding management (see Table 3 for details).

Functional and environmental tests were conducted in laboratories, on subsets of the float initially and then on the complete float. These tests allowed us to validate all the functionalities before float deployment at sea. In particular, the assessment of the hydraulic engine proved that the objective of 150 cycles at $4000 \mathrm{~m}$ was realistic.

Four floats were deployed between 2012 and 2014. One of them achieved 142 cycles with oxygen measurements and with its CTD pump running continuously. The energy balance was consistent with our assessments: regarding the battery levels of this float that cycled every 2 days, we estimate that the objective of 150 cycles will be reached in future floats doing 10-day cycles and CTD measurements only. The stability of the floats at parking depths and the regularity of their 


$$
\frac{1}{7}+\frac{1}{2}
$$


TABLE 5. Salinity correction for the four Deep-Arvor floats estimated by the OW method when considering layers deeper than $3000 \mathrm{dbar}$ or layers shallower than 2000 dbar or by comparison below 3000 dbar with a calibrated reference profile.

\begin{tabular}{|c|c|c|c|}
\hline \multirow[b]{2}{*}{ WMO No. } & \multicolumn{2}{|c|}{ Layers deeper than 3000 dbar } & \multirow[b]{2}{*}{$\begin{array}{l}\text { Layers shallower than } 2000 \mathrm{dbar} \\
\text { OW method (layers above } 2000 \mathrm{dbar} \text { ) }\end{array}$} \\
\hline & $\begin{array}{l}\text { Comparison with } \\
\text { reference CTD }\end{array}$ & $\begin{array}{l}\text { OW method (layers } \\
\text { below } 3000 \text { dbar) }\end{array}$ & \\
\hline 6901468 & 0.010 & $0.009 \pm 0.002$ & $-0.003 \pm 0.025$ \\
\hline 6901597 & & $0.020 \pm 0.002$ & $0.025 \pm 0.023$ \\
\hline 6901631 & 0.013 & $0.012 \pm 0.003$ & $-0.002 \pm 0.043$ \\
\hline 6901632 & 0.014 & $0.015 \pm 0.006$ & $0.026 \pm 0.029$ \\
\hline
\end{tabular}

down- and upcasts were demonstrated. The good quality and stability of the satellite telemetry performances were verified.

The data are of good quality, although a systematic bias of about 0.01-0.02 toward lower salinity levels was observed. As the bias is not pressure dependent and as the water mass is stable below $2000 \mathrm{~m}$, it is easily detected and corrected, which is not the case when considering the 0-2000-m layer only. However, according to the manufacturer, this bias could be due to technological issues on the conductivity sensor: a degradation of the "platine black" coating of the cell could lead to such a bias. Thus, these results reveal that beside the scientific use of the data below $2000 \mathrm{~m}$, extending the Argo array will also be useful in improving the overall quality of the salinity data in the 0-2000-m layer. Further studies, which are beyond the scope of this one, are required to better understand and correct the oxygen measurement bias and to determine whether the fresh bias is systematic, and more generally to improve the accuracy of the SBE 41CP conductivity sensor. We obviously do not rule out the possibility of equipping the Deep-Arvor with the SBE 61 sensor once it is commercialized if the SBE 41CP fails to show clear-cut improvement.

Finally, we succeeded in finding a cost-effective solution by streamlining our technological choices during the design of the float. If we compare the Deep-Arvor with the 2000-m regular version, then it is able to reach twice the depth $(4000 \mathrm{~m})$, with an additional capacity to travel $20 \%$ more of cumulated vertical distance, whereas its cost should remain less than twice the price of the standard float.

\section{Conclusions}

The scientific community needs to answer questions concerning ocean warming and sea level rise. Up to now profiling floats have been limited to 2000-m depth, which represents a capacity to monitor only $45 \%$ of the ocean volume. Floats have to go deeper, in order to provide a more accurate estimate of heat and freshwater oceanic content changes. This is the reason why the Deep-Arvor float was developed by Ifremer. This float offers good performance by combining features such as the capacity to perform 150 cycles of permanent pumping CTD profiles from $4000-m$ depth (up to $4100 \mathrm{dbar}$ ) to the surface, the good quality of data acquisition allowing the averaging of high rate samples for a better heat content balance, the near-real-time transmission of profile data, and the capability to detect and correct bottom groundings while remaining light, easy to deploy, and cost effective. Four prototypes were successfully tested at sea between 2012 and 2014. Thanks to this deep profiling capacity, we were able to identify a salinity bias of $0.01 \mathrm{psu}$, which would not have been detected with a standard Argo float.

Meanwhile, an industrialization phase was carried out with our partner NKE Instrumentation that led to the manufacturing of four new floats deployed in June and July 2015. The tests at sea are still ongoing, aiming to demonstrate that they match Deep Argo requirements, and in particular concerning their capacity to cycle without failure and to deliver good data quality during their mission. The first results are already promising and we feel confident that we will be able to achieve these aims.

This development and the associated experiments also reveal that particular care has to be taken regarding future sensor integration, as well as the necessity to work closely with the sensor manufacturers. For example, the need to do in-air oxygen measurements while the float is at the sea surface has been recently highlighted in order to improve the quality of oxygen data. We will take the Argo recommendations into account by implementing these features for future deployments in 2016. The Deep-Arvor is deployable everywhere regardless of the depth: thanks to efficient grounding management, water shallower than $4000 \mathrm{~m}$ can be addressed. However, solutions for preventing and avoiding the seabed while maintaining the capability of the float to sample down to the ocean bottom in water shallower than 4000-m depth will be investigated to reduce the risk of premature loss of the float. The ability to deploy the Deep-Arvor in icecovered areas is one of our concerns, which is why an 
ice-sensing algorithm combined with a postponement of the data transmission will soon be added to the float. Other possibilities to improve the lifetime of the float have been identified, including a different design of the engine. A promising study on this subject has already started.

Started in 2015 and ongoing in 2016, a pilot experiment (work package 5 of the NAOS project) plans to deploy 23 Deep-Arvor floats in the North Atlantic Ocean. Besides the scientific objective to monitor changes in deep-water mass properties and in ventilation pathways, the goal of this pilot experiment is to demonstrate that the Deep-Arvor can routinely meet the requirements of deep profiling and lifetime objectives with good and stable data. This phase started in summer 2015 when four Deep-Arvor were deployed from the R/V Thalassa in the North Atlantic Ocean during the Reykjanes Ridge Experiment (RREX) cruise. The results of the first months of successful deep profiling are very encouraging.

Acknowledgments. We sincerely thank the three anonymous reviewers for their comments, which helped improve this manuscript. This work was funded by the Euro-Argo project preparatory phase from 2009 to 2011 (Le Traon et al. 2010), and the Novel Argo Ocean Observing System (NAOS) project-one of the projects selected in the Equipex call for proposals of the French program "Investissements d'avenir," managed by the French National Research Agency under Reference ANR-10- EQPX-40-from 2011 to 2014 (Le Traon et al. 2012).

The industrial prototypes of the Deep-Arvor were manufactured by our industrial partner, NKE Instrumentation.

We thank the Strasse and the Geovide cruises and their corresponding teams for their participation in the deployment of the Deep-Arvor profiling floats and their operational support.

We particularly thank Nathanaële and Stephane for their help in the operations at sea, and Camille and Emlyn for their careful rereading of this article.

\section{REFERENCES}

Amante, C., and B. W. Eakins, 2009: ETOPO1 1 arc-minute global relief model: Procedures, data sources and analysis. NOAA Tech. Memo. NESDIS NGDC-24, 19 pp., doi:10.7289/ V5C8276M.

Bittig, H. C., and A. Körtzinger, 2015: Tackling oxygen optode drift: Near-surface and in-air oxygen optode measurements on a float provide an accurate in situ reference. J. Atmos. Oceanic Technol., 32, 1536-1543, doi:10.1175/JTECH-D-14-00162.1.

Church, J. A., J. M. Gregory, N. J. White, S. M. Platten, and J. X. Mitrovica, 2011: Understanding and projecting sea level change. Oceanography, 24 (2), 130-143, doi:10.5670/ oceanog.2011.33.

Freeland, H., and Coauthors, 2010: Argo-A decade of progress. Proceedings of OceanObs'09: Sustained Ocean Observations and Information for Society, J. Hall, D. E. Harrison, and D. Stammer, Eds., Vol. 2, ESA Publ. WPP-306, doi:10.5270/ OceanObs09.cwp.32.

Gaillard, F., T. Reynaud, V. Thierry, N. Kolodziejczyk, and K. von Schuckmann, 2016: In situ-based reanalysis of the global ocean temperature and salinity with ISAS: Variability of the heat content and steric height. J. Climate, 29, 1305-1323, doi:10.1175/JCLI-D-15-0028.1.

Garzoli, S., and Coauthors, 2010: Progressing towards global sustained deep ocean observations. Proceedings of OceanObs'09: Sustained Ocean Observations and Information for Society, J. Hall, D. E. Harrison, and D. Stammer, Eds., Vol. 2, ESA Publ. WPP-306, doi:10.5270/ OceanObs09.cwp.34.

Gruber, N., and Coauthors, 2010: Adding oxygen to Argo: Developing a global in situ observatory for ocean deoxygenation and biogeochemistry. Proceedings of OceanObs'09: Sustained Ocean Observations and Information for Society, J. Hall, D. E. Harrison, and D. Stammer, Eds., Vol. 2, ESA Publ. WPP-306, doi:10.5270/OceanObs09.cwp.39.

Johnson, G. C., J. M. Lyman, and S. G. Purkey, 2015: Informing Deep Argo array design using Argo and full-depth hydrographic section data. J. Atmos. Oceanic Technol., 32, 21872198, doi:10.1175/JTECH-D-15-0139.1.

Keeling, R. F., A. Körtzinger, and N. Gruber, 2010: Ocean deoxygenation in a warming world. Annu. Rev. Mar. Sci., 2, 199229, doi:10.1146/annurev.marine.010908.163855.

Kouketsu, S., and Coauthors, 2011: Deep ocean heat content changes estimated from observation and reanalysis product and their influence on sea level change. J. Geophys. Res., 116, C03012, doi:10.1029/2010JC006464.

Le Reste, S., and J. Gould, 2011: Euro-Argo: Global ocean observing infrastructure; Float technology analysis. Euro-Argo Rep. 4.2.1., 26 pp. [Available online at http://archimer.ifremer. fr/doc/00213/32417/.]

Le Traon, P.-Y., and Coauthors, 2010: Euro-Argo: Towards a sustained European contribution to Argo. Proceedings of OceanObs'09: Sustained Ocean Observations and Information for Society, J. Hall, D. E. Harrison, and D. Stammer, Eds., ESA Publ. WPP-306. [Available online at http://www. oceanobs09.net/proceedings/ac/index.php.]

_ , and Coauthors, 2012: NAOS: Preparing the new decade for Argo. Mercator Ocean-Coriolis Quarterly Newsletter, No. 45, Mercator Ocean, Ramonville Saint-Agne, France, 3-4.

Loaec, G., S. Le Reste, S. Le Bras, C. Gac, F. Marchese, P. Bouquet, and A. Deuff, 2004: Les flotteurs profileurs: État de la technologie et perspectives d'utilisation. Atelier Expérimentation et Instrumentation (AEI), Paris, France, INSU, IFREMER, and Météo-France, 6 pp.

Ollitrault, M., and J.-P. Rannou, 2013: ANDRO: An Argo-based deep displacement dataset. J. Atmos. Oceanic Technol., 30, 759-788, doi:10.1175/JTECH-D-12-00073.1.

Owens, W. B., and A. P. S. Wong, 2009: An improved calibration method for the drift of the conductivity sensor on autonomous CTD profiling floats by $\theta-S$ climatology. Deep-Sea Res. I, 56, 450-457, doi:10.1016/j.dsr.2008.09.008.

Piron, A., V. Thierry, H. Mercier, and G. Caniaux, 2016: Argo float observations of basin-scale deep convection in the Irminger 
Sea during winter 2011-2012. Deep-Sea Res. I, 109, 76-90, doi:10.1016/j.dsr.2015.12.012.

Purkey, S., and G. C. Johnson, 2010: Warming of global abyssal and deep Southern Ocean waters between the 1990s and 2000s: Contributions to global heat and sea level rise budgets. J. Climate, 23, 6336-6351, doi:10.1175/2010JCLI3682.1.

Roemmich, D., and Coauthors, 2009: The Argo Program: Observing the global ocean with profiling floats. Oceanography, 22 (2), 34-43, doi:10.5670/oceanog.2009.36.

Salvetat, F., 2011: Check of the calibration of the CTD serial number $2820 \mathrm{SBE} 41 \mathrm{CP}$. Ifremer, $9 \mathrm{pp}$. [Available online at http://archimer.ifremer.fr/doc/00062/17296/14807.pdf.]

Takeshita, Y., T. R. Martz, K. S. Johnson, J. N. Plant, D. Gilbert, S. C. Riser, C. Neill, and B. Tilbrook, 2013: A climatology-based quality control procedure for profiling float oxygen data. J. Geophys. Res. Oceans, 118, 5640-5650, doi:10.1002/jgrc.20399.

Trautmann, C., 2013: Filament wound housings for profiling floats. Workshop on Durability of Composites in a Marine Environment, Nantes, France, Ifremer, 1 pp. [Available online at http:// archimer.ifremer.fr/doc/00144/25484/23637.pdf.]

von Schuckmann, K., J.-B. Sallée, D. Chambers, P.-Y. Le Traon, C. Cabanes, F. Gaillard, S. Speich, and M. Hamon, 2014: Consistency of the current global ocean observing systems from an Argo perspective. Ocean Sci., 10, 547-557, doi:10.5194/os-10-547-2014.

Zilberman, N., and G. Maze, 2015: Report on the Deep Argo Implementation Workshop. Ifremer Doc. LPO-15-04, 36 pp. [Available online at http://archimer.ifremer.fr/doc/00281/39238/ 37799.pdf.] 